\title{
The application of innovative design concept in visual communication art design
}

\author{
Leng $\operatorname{Xin}^{1, a}$ \\ ${ }^{1}$ Jiangxi college of foreign studies,NanChang,330099, China \\ a LengXin@yeah.net
}

Keywords: Innovative design; Design concept; Visual communication; Art design; Application research.

\begin{abstract}
In recent years, visual transmission art design is gradually rising. As a kind of art concept, visual communication art design refers to the design of the visual language communication, communication mode, and the design of the visual symbols. Visual communication art design to business services as the object, the application of a very wide range of content, including the following: advertising design, store environment design, packaging design and corporate image design, etc.. Visual transmission art design has become the media between consumers, enterprises and commodities, and its innovative design is mainly divided into three aspects: visual language, design concept and performance of innovation. Based on the development of visual communication art, this paper focuses on the implementation of innovative design concept in visual art design. In the modern society, people's life rhythm accelerate, the rapid development of the mass media, the modern people every day can come into contact with a lot of information in visual design, visual communication design attracts more and more media attention, and color as an important element of visual communication design, it does not show its effect every hour and moment and power in art design. This paper mainly through the use of color in all areas of visual communication to analyze the specific visual communication design should be how to make reasonable use of color art, to create a good work.
\end{abstract}

\section{Introduction}

Visual communication design is the use of visual symbols to convey a variety of information design. The designer is the sender of the message, and the object is the recipient of the message. In short, the visual communication design is "to give people look at the design, to inform the design". This is a popular term popular in Japan in 1960, Tokyo held the world design congress [1] (P2), however, from the view of its development process, to great extent, it is the extension of printing art design and extension of the rise in the middle of the nineteenth Century in Europe and the United states. Visual communication design is based on the text, graphics and color as the basic elements of artistic creation, and the color is the first element to attract people's attention, psychology research shows that when people in the observation object, the first few seconds of color feeling symbolic accounted for $80 \%$, accounted for only $20 \%$, after two minutes, the sense of color occupy $60 \%$, while symbolic accounted for $40 \%$, five minutes each half, and this state will continue to maintain, that is to say, the design of visual color effect can cause strong public concern, therefore the color in the visual communication plays an important role in the design of. So what is visual communication design? Visual communication design is an art, it is an art, and it is because it is consistent with the characteristics of art [1]. Visual communication design refers to the visual function design, the traditional media such as newspapers and magazines and the Internet, and other printed publications, movies and television, billboards and other mass media have become the carrier of visual communication, which is a by the carrier to the relevant information to the eyes, so as to design performance modeling." Visual communication design is the basis for the design of the specific purpose, and analyzes the information and design through the basic elements of text, graphics, color and shape, is a process of information visualization will convey to the audience and the impact on the 
audience. Visual communication design is a modern commercial service art, including logo design, advertising design, packaging design, store environment design, corporate image design, simple, visual communication design is through the visual media to convey to the audience design. It is "to give people look at the design, to inform the design". Visual communication is generally summed up as: "who", "what", "to whom", "effect, the impact of how" four procedures. In our life, the visual communication design involves many fields, such as television, film, architecture, plastic arts, all kinds of design products, as well as all kinds of icons, stage, text design, etc.. So called "visual communication design", it plays the role of communication enterprise - commodity - consumer bridge. Visual communication design in the main text, graphics, color as the basic elements of artistic creation, the spirit in the field of culture with its unique artistic charm affects people's feelings and ideas plays a very important role in people's daily life. Visual communication design refers to the use of visual symbols to convey a variety of information design. The designer is the sender of the message, and the object is the recipient of the message. Visual design. Since the beginning of the new century, visual communication art design has been fully developed, and in the development process, it has experienced many twists and turns, from the development stage of commercial art to the development of graphic art. In twenty-first Century, visual communication art design gradually applied visual symbols to achieve the transmission of information. Visual communication art design in the current actual design, how too correctly and fully to the information to give people[2], is the core of the problem. However, in the current stage of development, the social environment is constantly complicated, the major media and technology continue to develop, only to solve the core issue of visual communication is far from enough. Therefore, the designers of visual communication design should be based on the social development needs and social emotions, in the visual communication design to establish innovative design concept, to innovation as the core.

\section{Innovative design concept in the implementation of visual communication art design}

Popularization and diversification. The application of visual communication art design in a wide range of fields, with popular, diverse forms of existence, the two are the opposite of each other. Visual communication art design in the development environment of our country, we must take the personalized design to the world, in order to break through the characteristics of china. First of all, the designer should understand the development environment Chinese, reconstruction design features in the design of personalized style diversification, and highlight the unique concept, grasp the characteristic of diversity. Secondly, the reasonable use of the designer. Because the picture carries the visual transmission art design concept, is the rich visual language. Finally, the art of visual communication design in art design, in addition to considering the public awareness, but also embody the Chinese national pattern cultural connotation, clarify the relationship between color and color of nationality unique features, combined with the national characteristics of culture and design thinking, design of modern and traditional styles of visual art effect.

Environmental protection and personalization. Visual communication art to reflect the modern style. Designers must fully understand the various aspects of society, a profound understanding of life, based on their own design basis to be supplemented, personalized design, to reflect the value and positioning. The designer should reflect the personalized design, first of all, to have a full understanding of the characteristics of consumers with innovative ideas as a starting point, identify the location, unique design style, and make personalized products with art and technology requirements, to the public a unique aesthetic feeling. Secondly, as the awareness of environmental protection gradually increased, the designers must have the idea of green design, design style based on the concept of environmental protection, design and analysis of its scientific, allow people to experience the beauty of nature and design works. With the people's aesthetic level and the needs of continuous improvement, and the traditional aesthetic concept there is a certain difference. Therefore, the designer's visual communication art design should have the innovative thinking with the times. The pace of people's life has gradually accelerated in the new century, which requires the convenience and rapidity of the goods. Therefore, the designer should design convenient and efficient 
products, meet the requirements of the people, so that people can have to find everything fresh and new feeling, can make the goods sales and good reputation, win a better propaganda effect. Visual communication art designer to master the requirements of people and thinking change, to achieve excellent works and publicity[3].

Have a keen eye for social life. Innovative ideas to be cut in reality, appropriate to life, can not be imagined. Designers should go deep into the life of the people, do a good job in the survey, in the social life of design inspiration, in order to design a work in people's daily lives in line with the needs of people. The designer to design a piece of artistic commodity, first of all, to have insight into the social life view, understand the commodity audience; secondly, the investigation of the audience aesthetic level, psychological needs, through investigation and analysis, the design of visual art of the goods according to the final results. Only in this way, designers can design to meet people's aesthetic level and the actual needs of the design of goods. Since the beginning of the new century, our country's employment is faced with great pressure. According to the goals and characteristics of college education, and visual communication requirements for the teaching of art design, visual communication design and the cultivation of independent innovation ability of students in the teaching of art design must pay attention to the concept of the effective combination of market demand and the cultivation of talents, the art of visual communication design of the practical requirements of the implementation of the students thought. Increase the professional students' practical operation ability, so that students can better adapt to the market competitiveness, so that students can meet the social needs of students, and comprehensively improve the employment rate of students.

\section{Application of color in visual communication design}

Logo design and color. With the rapid economic development, people's life rhythm is also greatly accelerated, the rapid development of all walks of life, so that modern people can access to a large number of corporate signs every day. This requires the logo to have a high degree of recognition, and color is in the first line of marketing contact, to attract the public's most important factors, it can reveal signs of change and development of the law. In the logo design, color is the designer in the eyes of the most lively and vivid, ebullience role, and can produce strong visual psychological effect, thereby enhancing the identification of signs, so we should pay attention to color logo design in the application. In the modern world of goods, the magic power of the color of the logo can be felt everywhere. We observe the color of the time, everyone will have their own understanding, it will cause people to experience the surrounding life and the environment of the association, which makes the color has a sense of well-being. Warm colors to red orange yellow, gives a warm, comfortable and happy feeling, it can attract people's attention, make people fast identification. Cool white, blue, green, although the color contrast is relatively low, but in order to give people a sense of novelty, deep and clear. For example, McDonald's logo is composed of red, yellow and white composition, strong visual impact to the human, capital letters like a golden arches, giving a cheerful and lively feeling, which caused a strong consumer desire to buy, but also to the propaganda effect on the enterprise image.

Logo design and color application. Logo design of the connotation of the color has a strong ideological and beyond, the use of color directly determines whether the success of our design. As a non linguistic sign language, the information is very limited, so we need a reasonable grasp of the use of color, so as to enhance the logo design to a proper height. Logo color design requirements: first of all, to be simple and powerful, can give a strong impression. Second, to comply with the brand or the characteristics of the industry. Finally, it is helpful to extend the application of visual recognition. Mark the color collocation should focus on considering the relationship between various hue, lightness and purity, study the different people of different colors and feel like. Logo color is best to use a color to unify the graphics, otherwise it will give people a messy, and difficult to identify the feeling, so that signs do not play a good role in the publicity. Logo design color collocation usually has three methods: one is the basic color collocation, color pure color, warm, and dazzlingly beautiful 
artistic effect and spread effect is good; two is the same color collocation, only select a color, using the method of color changes in brightness, color vision to form a transition from the shallower to the deeper, can express dynamic feeling; three is the color collocation, color configuration, in contrast, give a person with very strong visual impact. In specific logo design process, the different characteristics of the industry, it will affect the logo of the color design, we need to according to the characteristics and needs of different industries, choose the appropriate color. For example: Mark cosmetics or fashion color, we generally use low purity, gold and silver, gray, black, subtle colors, it represents fashion, fashion, introverted. Sign in the high-tech information industry color, we use cool colors, give a person with fast, rational, calm feeling. And in the food industry, we usually use warm colors, can give people a sense of warmth and happiness, and also can stimulate people's appetite [4]. Packaging design and color application. In color matching, how to reflect the color characteristics of goods is very important. In the design of packaging, packaging to avoid the use of color too much, gorgeous riotous with color may not make people love, sometimes people will have a dazzling sense, the proper use of simple color, in order to maximize the potential of color. In the packaging design, to skillfully use the color of the performance of the law, to fully play the role of a variety of colors, so as to arouse the interests of consumers, to promote the formation of their purchase behavior. In the packaging design, the choice of color form must follow two rules. First of all, the packaging color to highlight the characteristics of the goods. For example, chocolate brown, brown, orange and other colors Orange Juice symbol of goods are similar, we must consider this factor in the process of design. Secondly, according to the different consumption object, choose different packaging color. For example, children love red, orange and yellow, warm colors, bright and full of youthful spirit of young people, love highly pure color, while the old man is quiet, steady tone in love. There are a number of different ethnic religious beliefs, we should fully understand the different colors of the consumer preferences and taboos, which are directly related to the formation of consumer buying behavior. The packaging color design is the competitiveness of enterprise products at the forefront of competition. Therefore, we in the design process, not only to pay attention to commodity packaging color landscaping features, but also attach importance to the marketing function of commodity packaging color from the perspective of economics, according to the different color forms of different commodities, and fully meet the various attributes and functions of goods and meet the psychological needs of consumers, to enable enterprises to have more consumer groups in the fierce competition in the market to.

Advertising design and color application. Color for advertising design, it is like the muscles of people, is the advertising vigor and vitality, so the proper use of color is very important, otherwise it will reduce the advertising campaign. For example, cosmetics ads green, health, color on the use of neutral colors, such as green, white, etc.. Food ads are more red, yellow and other warm colors, in order to stimulate people's appetite and desire to buy. Industrial electrical and mechanical type of advertising emphasis on functionality and efficiency, color on the use of blue, purple and advanced gray tone, etc.. Designers should adopt different color schemes for different industries. There are a lot of commercial advertising has its own personality image. Generally speaking, in the process of our creative advertising, we should do the following [6] (P3): first, to analyze the feelings of consumers on the color, on the basis of the use of color to people with a novel, creative feeling. Second, advertising should be able to clearly reflect the use and characteristics of goods. Third, to increase the color brightness and purity, so it is more conducive to the consumer recognition. Fourth, the use of color to respect the different gender, different countries, different ethnic cultures and customs. For example, women prefer white, because white symbolizes purity, while men prefer blue, because blue symbolizes the bold, calm and mature. Islam, the green color of life, as yellow as the color of death. The Buddhist with yellow frock color, meaning extraordinary. We are in the process of advertising design must take into account the above factors, only in this way will be more conducive to enhance the propaganda of advertising.

The teaching mode based on employment orientation. The establishment of China's major of art design and media type of professional, the meaning of the field includes 5 aspects, namely, packaging design, web design, advertising design, display design, book design. And visual communication art 
design should be selected in the 5 fields. Under the guidance of the relevant professional teachers, students completed the graduation design process has the following. 1 design planning. The students are divided into several groups, referring to the field of design topics selected by the students, through the teacher's scientific guidance, carefully design the theme. Students according to the design of the style, to master the design of the subject of the design process, through the investigation and study to collect information related to the theme, through the multi-dimensional analysis, to develop a complete plan to meet the design theme. 2 design links. Through their sketches, and modifying and screening students according to teachers to determine the scheme, determine the design style, design of structure, graphics, reasonable collocation and arrangement by color, so that each group between the division of production. 3 the results of the design work. Students according to the design style of the effect, planning a demonstration program, the first ready to show the material before, pay attention to the design of the space relationship, showing their outstanding design works. School leaders can be invited to visit the student's work related enterprises, in order to hold student recruitment, to solve the problem of employment of students[5].

\section{Summary}

With the development of the information age, people's aesthetic level and demand continue to upgrade. The art of visual communication designers should have innovative ideas of keeping pace with the times, to personalize the visual characteristics of artistic works as the premise, not only to design to meet the people's aesthetic level and the actual needs of the work, but also reflects the modern green design works. Colleges and universities as a visual art to convey the important output of art design talents, not only to cultivate high-quality and high level of design ability of the students, but also to strengthen the cultivation of innovative design talents, in order to meet the development needs of visual art design, make the students innovative design concept by keeping pace with the times, to ensure China's art of visual communication design in the development of stable and fast.

\section{References}

[1] Liu Haitao. The teaching mode of "studio" teaching mode of visual transmission art design in Higher Vocational Colleges [J]. modern vocational education. 2016 (13).

[2] Shen Binbin. Analysis of the innovative design concept of visual communication art [J]. art education research. 2015 (09).

[3] package. His visual art and culture industry to study the relationship between [J]. of popular literature. 2014 (09).

[4] Liu, sun ting. Visual communication art design local curriculum "visual rhetoric" teaching research [J]. public literature and art. 2016 (01).

[5] Shang Chun Ling. How to do visual communication art design with the times [J]. Journal of Anshun University. 2016 (02). 